\title{
The Issue of Normativity and the Methodological Implications of Interpretivism I: The Idea of Normative Guidance
}

\begin{abstract}
The article is the first part of an analysis that seeks to clarify the distinctive normativity of law, as it is reflected in the legal systems of constitutional democracies. It explores the ability of interpretive theories to capture the conceptual characteristics of the normativity of law. The normative guidance the law provides is characterised in terms of normative claims. Normative claims are construed as being based upon linking up expectations with practical reasons. The analysis lays out the conditions of providing normative guidance with the help of drawing a distinction between the success and efficacy of normative claims. The success of normative claims is explained in terms of their substantive justificatory background and the competence of those making them. The characterisation of the efficacy of normative claims is based on the distinction between instrumental and non-instrumental reasons.
\end{abstract}

Keywords: interpretivism, normative guidance, normative claim, practical reason, practical justification, instrumental and non-instrumental reasons

The present article revolves around the distinctive normativity of law, and it will remain within the boundaries of conceptual analysis. I restrict myself to unpacking some of the conceptual implications of a more or less undisputed claim: 'The law is a normative and institutional social practice. ${ }^{\text {' I }}$ have kept returning to this point over the past few years, ${ }^{2}$ but I would like to provide a more systematic inquiry that aims at a higher level of methodological awareness. I try to be systematic even if it sometimes means that I make rather trivial claims or touch upon issues that cannot be addressed adequately here. I map the relevant issues as carefully as I can.

I emphasise that this is primarily a methodological piece. My main concern is testing the ability of interpretive legal theories to capture the conceptual characteristics of the normativity of law. I explore the peculiarities, structures and limitations of interpretive theorising.

The specific strategy of explication I deploy here is partly explained by the fact that I am not entirely happy with the way debates on normativity are conducted in the contemporary (mainstream) legal theoretical discourse. The issue of normativity has become a battleground where the controversy between legal positivism and the natural law

* Senior lecturer, University of Aberdeen, School of Law, Elphinstone Road, Aberdeen, AB24 3UF, United Kingdom.

E-mail:m.bodig@abdn.ac.uk

1 This claim as a slightly more specified version of Neil MacCormick's starting point for his account of law: 'law is an institutional normative order.' See his Institutions of Law. Oxford, 2008, 11.

2 See Bódig, M.: Jogelmélet és gyakorlati filozófia: Jogelméleti módszertani vizsgálódások. Miskolc, 2004, chaps. 3-4 and 35. See also Bódig, M.: The Political Character of Legal Institutions and Its Conceptual Significance. Acta Juridica Hungarica, 46 (2005) 1-2, 33-50, 34-36. 
doctrine is played out. ${ }^{3}$ Analyses are too often driven mainly by the ambition to 'wrongfoot' the opponents in that particular debate. Accounts of normativity are too often contextualised in ways that sideline important aspects of the methodological challenges involved. To resist this tendency, this time around, I do not write a polemic piece. ${ }^{4}$ Although I track the sources of the ideas I rely on, most of the time, I do not seek out the theorists who may have a quarrel with my account. I rarely criticise anyone directly. I want to circumvent most of the characteristic debates in contemporary legal theory (especially the methodological debates about legal positivism, descriptivism and the separation of law and morality).

The substantive analysis that I offer is divided into four sections. The first one outlines the methodological programme (that is tested in this article for its ability to account for the normativity of law). The second section focuses on the idea of normative guidance, and then the second sets out to clarify the relationship between normative claims and practical reasons. The fourth section brings together the conceptual elements elaborated in the previous two sections, and lays out an account of the normativity of law. As the analysis is rather extensive, the fourth section (together with the Conclusion) will be published in Part II of this article. ${ }^{5}$ Here, in Part I, I focus on the underlying methodological and conceptual issues without which the explication about the normativity of law in Part II would make little sense.

\section{Interpretivism}

I need to start with clarifying what I mean by interpretivism about legal theory. I associate the fundamental idea with a methodological challenge facing all legal theories. Each legal theory needs to rely on a 'background epistemology' that concerns the ways in which one can reveal theoretically relevant facts and ideas. The background epistemology provides the methodological basis for the truth-claims of the theory. This is what makes the theory intelligible - enabling others to figure out what counts as a justification for the theory (or as a meaningful challenge to it).

Interpretivism is one possible background epistemology for legal theory. ${ }^{6}$ Interpretive theories of law gather the 'data' that underlie their theoretical claims from participant communication about legal practices. They assume that the way competent participants (that is, mainly lawyers) communicate about the legal practice is revealing about the character of law. Interpretive theories construe law as a social practice whose features can

3 Two of the important pieces demonstrate this point pretty clearly. Gerald Postema's 'The Normativity of Law' [in: Ruth Gavison (ed.): Issues in Contemporary Legal Philosophy. Oxford, 1987] is primarily a critical appraisal of Hart with a strong anti-positivist edge. Part Two of Jules Coleman's The Practice of Principle (Oxford, 2001), entitled 'The Possibility and Normativity of Law', is mainly an apology of legal positivism.

${ }^{4}$ I do not claim neutrality in the debate about positivism. See Bódig, M.: Interpretivism and Conventionalism: Contributions to the Critical Assessment of Contemporary Methodological Legal Positivism. In: Asifa, B. (ed.): Legal Positivism: Conceptual Approach. Hyderabad, 2008. See also Bódig, M.: Legal Positivism and the Limits of the Contemporary Legal Theoretical Discourse. German Law Journal, 12 (2011), 625-662.

5 See issue 3 of Acta Juridica Hungary (2013) (forthcoming).

${ }^{6}$ Cf. Bódig: Interpretivism and Conventionalism... op. cit. 155-158. See also Bódig, M: Jogelmélet és gyakorlati filozófia. op. cit. 446-455. 
be revealed, with sufficient adequacy, by way of identifying juridical concepts and interpreting their characteristic uses in participant communication. ${ }^{7}$

It was Herbert Hart who made interpretivism the dominant background epistemology for mainstream legal theories. ${ }^{8}$ It was a pivotal aspect of his methodological vision that the analysis of legal concepts must be interpretative ('hermeneutic'). ${ }^{9}$ For him, the remit of legal theory was to elucidate the conceptual implications of our familiar ideas concerning law and our ways of communicating legal claims. Naturally, Hart's interpretivism was developed as an integral part of his methodological positivist enterprise, ${ }^{10}$ and it is largely due to his influence that most contemporary positivists embrace interpretivism in some form. ${ }^{11}$ But interpretivism is not simply a positivist enterprise. Over the past few decades, a variety of interpretivist frameworks has emerged - a number of them designed for the purposes of post-positivist or anti-positivist theories. ${ }^{12}$ (Dworkin's legal theory is probably the best known among them. ${ }^{13}$ ) Although there is a committed 'anti-interpretivist' strand in contemporary legal theory, ${ }^{14}$ I do believe that the spread of interpretivist methodology is an encouraging development. ${ }^{15}$ This is one of the good things that came out of Hart's legal theory.

7 As to alternative background epistemologies legal theory, one can think of transcendentalism (characteristic of Kelsen's 'pure theory of law'). See e.g. Hans Kelsen's characterisation of 'ought' as a transcendental category in his Introduction to the Problems of Legal Theory. Oxford, 1992, 23-25. Another alternative is empirical reductionism. For an instructive example, see the first edition of Karl Olivecrona's Law as Fact (London, 1939). And one can also reckon with the kind of constructivist legal epistemology that emerged in the 1980s. See Teubner, G.: How the Law Thinks: Toward a Constructivist Epistemology of Law. Law and Society Review, 23 (1989), 727-758.

${ }^{8}$ As to its intellectual origins, Hartian interpretivism can be traced back to Max Weber's 'interpretive' methodology for sociology. Cf. Weber, M.: Economy and Society: An Outline of Interpretive Sociology. Berkeley (CA), 1978. For an account of the Weberian influence on Oxford jurisprudence, see Finnis, J.: Philosophy of Law. Oxford, 1991, 211. Weber's ideas seem to have influenced Hart by way of Peter Winch's seminal The Idea of a Social Science and Its Relation to Philosophy (London, 1958). For Hart's reference on Winch, see his The Concept of Law. 2nd ed. Oxford, 1994, 289. For an analysis of the way Hart's account is related to Winch, see Veronica Rodriguez-Blanco: Peter Winch and Hart, H. L. A.: Two Concepts of the Internal Point of View. Canadian Journal of Law and Jurisprudence, 20 (2007), 453-473.

9 See. Hart, H. L. A: Essays in Jurisprudence and Philosophy. Oxford, 1983, 13.

10 Cf. Bódig: Interpretivism and Conventionalism... op. cit. 158-161.

11 See e.g. Raz, J.: Ethics in the Public Domain. Oxford, 1994, 215 and 237.

12 See MacCormick: Institutions of Law. op. cit. 5 and 295. For MacCormick's post-positivist credo, see ibid. 278-279. For an anti-positivist version of interpretivism, see Simmonds, N. E.: Law as a Moral Idea. Oxford, 2007, esp. 23 and 55. Even John Finnis adopts an interpretivist starting point for his legal theory. See his Natural Law and Natural Rights. Oxford, 1982, 3.

13 See especially Dworkin, R.: Law's Empire. London, 1986, 12-14. Some argue that interpretivism itself is to be identified with Dworkinian jurisprudential methodology. See Stavropoulos, N.: Interpretivist Theories of Law. In: Stanford Encyclopaedia of Philosophy (http://plato.stanford. edu/entries/law-interpretivist). I tend to think that such claims are misleading, and unduly simplify the development of interpretivism in legal theory.

14 See Moore, M. S.: The Interpretive Turn in Modern Theory: A Turn for the Worse? Stanford Law Review, 41 (1989), 871-957. Postema, G. J.: Jurisprudence as Practical Philosophy. Legal Theory, 4 (1998), 329-357, 329-330.

15 Cf. Bódig: Interpretivism and Conventionalism... op. cit. 156-157. 
The main attraction of interpretivism is that it enables theories to build on the familiar features of our legal practices. Interpretive legal theories work with (or, at least, start with) conceptual structures that should be readily recognisable for any competent practitioner. (They purport to work with familiar concepts like 'right', 'rule', 'obligation', 'official', and calibrate their meaning on the way they are characteristically used by practitioners of law.) At first glance, interpretivist theories seem to be uniquely well positioned to mediate successfully between abstract theoretical ideas and everyday experiences.

But interpretivism is not without drawbacks. Some of its methodological implications are bound to raise quite tricky challenges. By definition, the interpretive data that the theory works with come from particular practices that are contingent and historically constituted. Interpretive data are rooted in participant communication about the practice. They are, ultimately, all contingent (and often controversial) discursive constructions. Their analytical relevance cannot be fully specified outside the discursive context in which they were formed. As a result, by opting for interpretivism, the theorist brings into her account of law a good deal of contingency - and dealing with that contingency becomes one of her main methodological concerns. The theorist needs to be capable of skilfully 'managing' the interpretive data if she is to come up with plausible and important theoretical claims insights that can go beyond the idiosyncrasies of particular practices.

This is a particular challenge for theoretical accounts of normativity. Although participant communication is rich in interpretive data that are revealing about normative phenomena (mainly because lawyers have developed sophisticated terminologies for normative phenomena), it is difficult to find participants who consciously use the very concept of 'normativity'. The available interpretive data systematically underdetermine the theoretical accounts built upon them.

Faced with such difficulties, interpretive legal theory needs to fill conceptual gaps, and filter out some of the controversies among participants. (This is what I mean by managing the interpretive data.) If interpretivism is the background epistemology for the theory, definitional fiat will be a necessary part of managing the interpretive data. Interpretive analysis is likely to open up several pathways that lead to a variety of accounts of law with different theoretical advantages and disadvantages. ${ }^{16}$ I do not mean it as some sort of criticism. I see no reason to think that the challenges cannot be handled in a satisfactory manner-mainly because I am not particularly worried about the role of definitional fiat in legal theory. I cannot imagine how a legal theory can be free of definitional fiat (and why it should be). Theory-making is a constructive enterprise - especially in law. And, most importantly, I see no attractive methodological alternative to interpretivism in legal theory.

Such methodological challenges point to at least three important methodological implications for an interpretivist account of law. The first is that interpretivism sits uneasily with attempts to develop general theories of law (that are supposed to capture the conceptual foundations for all possible legal systems). Although the stark issues that interpretivism raises about the viability of general theories of law are important and revealing, I will not pursue them in any detail here. ${ }^{17} \mathrm{I}$ just note that I have no use for a general theory of law,

16 Cf. Bódig: Legal Positivism and the Limits... op. cit. 658-660. See also Perry, S.: Interpretation and Methodology in Legal Theory. In: Marmor, A. (ed.): Law and Interpretation: Essays in Legal Philosophy. Oxford, 1995, 123.

17 For my earlier take on the issue, see my Jogelmélet és gyakorlati filozófia. op. cit. 450-451. See also Waldron, J.: Can There Be a Democratic Jurisprudence? Emory Law Journal, 58 (2009), 
and I do not attempt to provide one. I theorise about the legal systems that my interpretive data come from: certain incarnations of 'state-law', 18 the legal systems of a few constitutional democracies.

The second implication of interpretivism is that there is no reason why interpretive analysis should stop at the conventional topics of legal theory (like the concept of 'legal obligation' or the relationship between law and morality). The available interpretive data associate the law with political ideas and values that profoundly shape the way that law is perceived by the participants of the practice. Interpretive legal theory cannot easily pass such issues (like the legitimacy of law) on to normative political theory. Interpretive analysis can and should extend to political values that are constitutive of legitimating discourses systematically linked to the legal practice. This is a crucial methodological issue for legal theory but I set it aside here as well (except for a few comments at the very end in Part II).

I dedicate this analysis to a third implication of the methodological peculiarities of interpretivism: one should come to terms with the 'double contingency' of theoretical accounts. On the one hand, the explanatory scope of an interpretive theory is limited by the contingency of its interpretive data (that tie it to particular and historically constituted practices). On the other hand, the explanatory scope of an account of law is limited by the contingency of the conceptual devices that are used to organise the interpretive data into a coherent structure. My chief ambition in this piece is to explore the interplay of interpretive data and definitional fiat in interpretive theorising - mainly because it is so rarely acknowledged. For that reason, I do not even try to offer the one and only plausible account of normativity of law. My account is one of several possible accounts that an intelligent observer or participant can put together from the conceptual elements 'floating' around in mainstream legal theory (when we reflect on ordinary experiences of law in a contemporary constitutional democracy).

Embracing contingency in this way may be unusual in contemporary legal theory. But, to me, this is the inevitable implication of a crucial methodological point: I deny that particular accounts of the conceptual features of law can be equally adequate for the purposes of sociological, doctrinal and critical understandings of law. ${ }^{19}$ I also believe that the kind of contingency I embrace raises no methodological difficulty for legal theoretical efforts that are consciously and carefully adjusted to well-defined theoretical ambitions. My own analysis, for one, is targeted to doctrinal understandings of law. In an important sense, this analysis is part of my efforts to develop a methodological perspective for legal theory that facilitates fruitful communication with legal doctrinal scholarship. ${ }^{20}$

Before I start my analysis in earnest, I must note a few features of the way this piece has been constructed. As I have mentioned above, my analysis is structured by a way of combining the interpretation of ordinary legal experiences and acts of definitional fiat. To keep their interplay more transparent, I have organised the discussion in a way that makes

675-712, 675-679. For a sophisticated defence of the idea of general jurisprudence, see Raz, J.: Between Authority and Interpretation. Oxford, 2009, 17-46.

18 Cf. MacCormick: Institutions of Law. op. cit. 12 and 169.

19 See Bódig, M.: Legal Theory and Legal Doctrinal Scholarship. Canadian Journal of Law and Jurisprudence, 23 (2010), 483-514, 510-513.

20 See ibid. 494-506. 
them easier to distinguish. Although I use a real-life example as my guide, the analysis is 'front-loaded' with elements of definitional fiat. (Most importantly, they permeate the way I make sense of the idea of 'normative guidance.') I wanted to avoid 'drip-feeding' my readers with contingent conceptual devices scattered all over the analysis. I wanted to make clear how much of definitional fiat is really required for an account of even moderate complexity in an interpretivist framework. I specify a terminology without claiming that it is directly warranted by the practices I talk about. Alternative terminologies may be no less adequate. My terminology comes mostly from intuition calibrated on contemporary theoretical literature, and articulated with a view to the conceptual needs of this particular investigation. In later sections, where I talk of law more specifically, I offer more from genuine interpretive analysis. This is especially characteristic of my account of the distinctive normativity of law in Part II. But even there, I remain on a pretty abstract level. All through the analysis, I use interpretive data sparingly. ${ }^{21}$ A more detailed interpretive analysis would have been a whole lot more extensive: it would have prevented me from providing an account that is at least 'structurally complete'. Even when I give a different impression, this remains a predominantly methodological piece: the abstract demonstration of a methodological vision.

\section{The idea of normative guidance: the preliminaries}

The interpretive data on normativity are frighteningly complex but they seem to converge on an abstract point: normative phenomena are inherently connected to human action. In all their forms, they are about guiding human action (specifying, in one way or another, what to $d o$ ) and providing standards of evaluation. ${ }^{22}$ Normative claims and normative mechanisms are directed at influencing human action, and they fulfil their distinctive functions only if they have an impact on how actions are formed or action problems are perceived and evaluated. In other words, the conceptual core of the idea of normativity is that of normative guidance. Our first task is to explore this very idea in some detail.

\subsection{An example: the prohibition of direct discrimination}

To stay true to the interpretive character of my methodological vision, I conduct an analysis organised around a particular normative claim that I take from the contemporary law of the United Kingdom. I will try to make sense of its ability to provide normative guidance. I deliberately chose an example that is a relatively recent addition to statutory law, and that makes perfect sense as a mere moral or political claim. That will allow me to have a look at it as a non-legal norm before asking what happened to it, in terms of its normative character, when it came to be institutionalised in legal form.

The norm I analyse is the statutory prohibition of direct discrimination. This is what makes it true to say that 'Treating others less favourably on certain prohibited grounds is illegal in the United Kingdom.' Although British lawyers would agree that this is true, there

${ }^{21}$ I also rely on a narrow informational basis: my interpretive data mainly come from the legal system of the United Kingdom. But I could have used equivalent interpretive data from the legal system of any other constitutional democracy I am familiar with - like Hungary.

${ }^{22}$ This is, admittedly, a Hartian way of capturing what normativity lies in. See e.g. Hart, H. L. A.: Essays on Bentham. Oxford, 1982, 18. 
is no single provision that expresses the claim in this explicit form. The normative claim is constituted by the interplay between a number of statutory provisions and certain contextual features of the relevant piece of legislation: Equality Act 2010. The key provision is section 13(1) of the Act that stipulates that 'A person $(A)$ discriminates against another $(B)$ if, because of a protected characteristic, ${ }^{23} A$ treats $B$ less favourably than $A$ treats or would treat others. ${ }^{24}$

It is also of some importance for my analysis that this is a norm that comes with an obvious rationale. Direct discrimination is to be prohibited because discriminatory practices are an affront to equality. The fight against discrimination is an aspect of the fight for equality in a democratic society. ${ }^{25}$

I will not attempt to provide an exhaustive analysis of the statutory prohibition of direct discrimination. ${ }^{26}$ I focus on one aspect that I am particularly interested in. If we look closer, we see that our norm combines the features of constitutive and regulative rules. ${ }^{27}$ (It is constitutive of what we mean by 'direct discrimination' in the context of legal procedures in the UK.) However, I will concentrate only on the way it operates as a regulative rule: the way it purports to guide action. When we look at the norm in its regulative function, what we already know about it outlines a distinctive conceptual structure: it makes reference to certain forms of action, normatively qualifies them (as 'prohibited' or 'illegal'), and it establishes a justificatory link between the normative qualification and a background justification. I set out to clarify, to some extent, how the interplay of these three elements constitutes normative guidance.

I do not claim that I have revealed here a conceptual structure that can be found in all legal norms. (That would be pretty silly to claim: legal norms come in rich structural varieties.) But I believe that it is pretty ubiquitous in the legal systems of constitutional democracies, and that it is informative about the normativity of law. ${ }^{28}$

23 'Protected characteristics' are listed in section 4 of Equality Act 2010: age, disability, gender reassignment, marriage and civil partnership, pregnancy and maternity, race, religion and belief, sex and sexual orientation.

${ }^{24}$ On the face of it, this is actually a descriptive claim that explains what 'direct discrimination' means. But there can be no doubt that it is normatively qualified as 'prohibited'. Equality Act 2010 contains a series of further provisions that make more explicit normative claims about the legality of discrimination - including direct discrimination. For example, s. 39(1) stipulates that 'An employer $(A)$ must not discriminate against a person $(B)(\ldots)$ in the arrangements $A$ makes for deciding to whom to offer employment...'

${ }^{25}$ This association with the ideal of equality is advertised in the very title of Equality Act 2010. Also, we read in $\S 10$ of the Explanatory Notes that 'The Act has two main purposes - to harmonise discrimination law, and to strengthen the law to support progress on equality.' Actually there is a particular vision of equality manifested here: predominantly formal equality as opposed to substantive equality, and equality of opportunity as opposed to equality of outcome.

${ }^{26}$ I admit that my characterisation of the norm is still not complete. Most importantly, I have not made it clear that direct discrimination is not prohibited in all areas of social life. UK antidiscrimination law covers only services and public functions (Part 3), premises (Part 4), work (Part 5), education (Part 6) and associations (Part 7). But I hope that we already have a useful template for the analysis.

${ }^{27}$ For the distinction, see Searle, J. R.: Speech Acts: An Essay in the Philosophy of Language. Cambridge, 1969, 33.

${ }^{28}$ I acknowledge that it is more typical that norms are analysed in terms of operative facts and their normative consequences. See e.g. MacCormick: Institutions of Law. op. cit. 24-28. See also 
For a good while in my analysis, I would like to forget that this norm is part of a particular legal system. (I will only provide a more detailed characterisation of it as a legal norm in Part II.) Here, I will look at it as a normative claim outside the boundaries of law. The prohibition of direct discrimination facilitates such an analysis pretty nicely. Only a few decades ago, it was still not part of the law in the UK. ${ }^{29}$ It is also important (and helpful) for my analysis that the underlying normative idea was not even a broadly accepted moral requirement from the outset. No doubt, some people passionately supported it, but others were ready to go with it reluctantly at best. Further others were uncomfortable with it (because they were worried about the implications for rearranging patterns of social interaction). And still further others rejected it as an aspect to and illegitimate form of social engineering by nosey liberals. It started off as a normative claim associated with a good deal of moral and political controversy.

What can we say about the 'normative quality' of the claim if it is made outside the boundaries of source-based law? ${ }^{30}$ We know that, even in the 1950s, one could say (and many did) quite meaningfully something like this: 'Treating people less favourably just because they are of a different colour or gender is wrong: if we truly respect the moral equality of persons, we must stand up against discrimination.' Was this claim capable of normative guidance ${ }^{31}$

\subsection{Practical reasons}

Before we can answer this question, we need to start with developing a fitting terminology. It will come with an abstract characterisation of normative guidance that is tailored to the purposes of my analysis. That will enable me to articulate better what I mean by normative guidance. We can start with a general interpretive claim about normative phenomena. Our language of normative phenomena (i.e. the language that we use to communicate what it means to act on an instruction or how we apportion blame for violations of normative requirements) suggests that normative guidance is not simply about getting people to do what others want them to do. The idea of compliance is constitutive of normative guidance. Guiding action is normative only when it becomes effective through compliance. ${ }^{32}$

MacCormick, N.: Rhetoric and the Rule of Law. Oxford, 2005, 24-25. It is quite possible that the traditional way of analysing the structure of norms is superior to mine. But the structure I outline here works better for my investigation.

29 The underlying normative idea (defining unlawful direct discrimination in terms of treating others less favourably on prohibited grounds) first figured in s. 1 of Race Relations Act 1968. The particular wording of s. 13 of Equality Act 2010 can be traced back to s. 1 of Sex Discrimination Act 1975.

30 On the concept of 'source-based law', see Raz: Ethics in the Public Domain. op. cit. 211.

31 I admit that the example I rely on is suspiciously convenient in an important respect. One can envisage it as either a legal or a moral claim without any significant change in the way it is formulated. Of course, there are many legal norms that are not this similar to their moral counterparts. Some moral claims are profoundly reformulated when they become legal norms. E.g. I have a moral reason to contribute to the costs of public services but the law transforms it to an obligation to pay specific taxes. There are important questions one can raise about such 'transformations'. I sought to set aside those issues here.

${ }^{32}$ It is for this reason that no one would characterise as an instance of normative guidance when someone is subjected to direct physical duress (e.g. when someone is tied to a seat and taken somewhere), or when someone's unconscious state (like that of being intoxicated) is manipulated to 
My account of normative guidance is meant to be a way of unpacking the implications of the constitutive relationship between normative claims, guidance and compliance. The organising idea is that normative guidance (in itself) does not force or even compel anyone to act upon it - at least in the sense of excluding alternative courses of action. ${ }^{33}$ The act by the addressee remains, so to say, voluntary. ${ }^{34}$ She still controls her own behaviour when accepting normative guidance. It remains a matter choice for the addressee whether she complies.

One way to explain the impact of normative claims on human action is to say that normative guidance interferes with the way intentions are formed. This is what legal theorists normally do, ${ }^{35}$ and I go along with the orthodoxy. It is of central importance for my analysis that this 'interference' takes place in the discursive dimension of human action: it is normative claims that make some impact. Normative guidance manages to influence the agent's intentions mainly by way of altering the 'discursive parameters' of her own perception of the pertinent action problems. By definition, nothing becomes a factor in normative guidance that cannot play a role in intersubjective practical discourses or, more specifically, deliberative processes targeted at human action. Normative guidance is a communicative process: what is normative can always be a matter of expression and discussion. $^{36}$

I will keep in focus the conceptual links between normative guidance, normative claims, discursive processes and intentions by relying on a particular terminological framework: that of the theory of practical reasons. ${ }^{37}$ My ambitions in this analysis could be understood as targeted at clarifying the types of reasons that have a constitutive role in generating normative guidance.

I construe practical reasons as thoroughly discursive phenomena. By practical reasons, I mean discursive constructions designed to address action problems. (That should not come as a surprise: in an interpretive framework, it is difficult to imagine any other way to go about conceiving of them. ${ }^{38}$ ) This implies that there is no normative guidance without the constitutive role of practical reasons. Efforts to influence behaviour are not instances of normative guidance unless they can be analysed in terms of providing practical reasons.

achieve a certain outcome. In such cases, the role of compliance is neutralised in a way that makes it impossible to talk of normative guidance. Indirect duress (that is, coercion), e.g. when someone is made to do something due to threats, is a more complicated case. I talk about it in detail below.

33 This is a surprisingly underappreciated aspect of normativity in legal theory. The law operates by using, as opposed to suppressing, the agency of humans. See Waldron, J.: The Concept and the Rule of Law. Georgia Law Review, 43 (2008), 1-61, 26.

34 On the sense of 'voluntary action', relevant here, see Anscombe, G. E. M.: Intention. Oxford, 1957, 33-34.

35 See e.g. MacCormick: Institutions of Law. op. cit. 103.

36 This is a reflection of John Searle's principle of 'expressibility': 'whatever can be meant can be said.' See his Speech Acts... op. cit. 19.

37 The way I use the concept of 'practical reason' relies heavily on Joseph Raz's theory. See Raz, J.: Practical Reason and Norms. 2nd ed. Princeton, 1990, 15-22. But the peculiarities of my approach warrant a series of deviations and adjustments that I do not keep track of.

${ }^{38}$ It is possible that the most obvious alternative route (that seeks to reduce reasons to psychological phenomena like 'conviction' and 'desire') is philosophically implausible. See e.g. Stoutland, F.: The Real Reasons. In: Bransen, J.-Cuypers, S. E. (eds): Human Action, Deliberation and Causation. Dordrecht, 1998, 43-44. By I do not pursue that issue here. 
Due to certain features of my account (that will become gradually clearer below), I need to link this idea of practical reasons quite intimately to a couple of considerations about practical justification. I believe that, if we characterise reasons as discursive phenomena, we can usefully clarify them by revealing the 'job' they do in communicative processes associated with practical justification. Practical reasons have a distinctive (and character-determining) role in the discursive process of justifying action to others and ourselves. ${ }^{39}$ As a result, the justification of action can always be represented in the following form: 'I believe that $\varphi$-ing is justified because...' Whatever comes after the 'because' in a meaningful way, regardless of any further categorical specification, qualifies as a practical reason. ${ }^{40}$

Of course, I do not try to tackle here the complex issue of what 'justification' is. But I cannot avoid highlighting two considerations that have far-reaching implications for my approach. (Below, I will add further clarifications that make my account slightly more specific.) First, practical justification aims at depicting the action as both intelligible and reasonably acceptable $e^{41}$ - under the given circumstances, from the affected agents 'point of view. One can say that justification aims at merging the perspectives of the claimants and the addressee to facilitate the development of mutually acceptable judgments on the pertinent action problems. The constitutive role of the affected agents' point of view implies that the subjects and the addressees of justification can only be rational beings.

Secondly, justification is a defensive process. ${ }^{42}$ It becomes necessary when objections are raised about a course of action, or if the agent is aware that her behaviour is vulnerable to possible objections. The need for practical justification arises when the agent (or someone else who cares about the way the pertinent action is assessed) perceives these objections as challenges that warrant a response. ${ }^{43}$ The importance of this consideration lies in the fact that, if added to the first one, it implies that justification is necessarily a relational concept. We can make sense of it only in specified discursive contexts structured by interpersonal relations. Justification is thoroughly communicative. More exactly, the conditions of success for practical justification in light of normative claims are thoroughly determined by the constitutive rules of the discourses that provide their communicative context.

\subsection{Direct normativity and the role of expectations}

Now that we have a terminological focus, we can make the idea of normative guidance a bit more specific for the purposes of this analysis. The very idea of normative guidance does not imply that the practical reasons that happen to shape the agent's intentions are always

39 As I believe that justifying in front of others has a sort of analytical priority, I set aside issues concerning justifying to ourselves.

40 Cf. Ricoeur, P.: Practical Reason. In: Ricoeur, P.: From Text to Action: Essays in Hermeneutics II. London, 1991, 189. For a more comprehensive, but similarly functional, clarification of the concept of 'reason', see Davidson, D.: Actions, Reasons, and Causes. In: Davidson: Essays on Actions and Events. Oxford, 1980, 3-4.

${ }^{41}$ The role of practical reasons in my account is predicated on an inherent connection between 'sensitivity to reasons' and reasonableness. Cf. Raz, J.: Engaging Reason: On the Theory of Value and Action. Oxford, 1999, 19-20.

42 Cf. Simmons, A. J.: Justification and Legitimacy: Essays on Rights and Obligations. Cambridge, 2001, 124.

43 My views on practical justification rely on Carl Wellman's model of 'challenge and response'. See his Challenge and Response: Justification in Ethics. Carbondale and Edwardsville (Ill.), 1971. 
deliberately provided by others. The interpretive data I work with, however, all originate from social practices in which making normative claims with a view to having an impact on the behaviour of certain others plays a constitutive role. (That is why I tend to call the subjects of normative guidance 'addressees'.) What my analysis revolves around is actually a particular mode of normativity that we could call 'direct' normativity. Direct normativity is built on the social relations of actual persons, and is manifested in the practice of making normative claims (e.g. when someone gives instructions to others, when a recognised authority makes rules for a class of addressees, and even when someone seeks to make an impact on others by judging their behaviour).

I concentrate my attention specifically on direct normativity because this is what we need to get closer to the legal theoretical implications of the analysis (that will be revealed in Part II). I assume that the law, in its entirety, functions within the framework of the intersubjective practice of reason-giving: legal norms never arise without human actions consciously targeted at creating them. One way to express this idea is that I will try to capture the normativity of law within the boundaries of a 'social constitutional model'. ${ }^{44}$

Quite obviously, the emphasis on direct normativity puts the concept of 'normative claim' at the centre of my analysis. ${ }^{45}$ I speak of normative claims when particular agents, with the specific intention of influencing behaviour, form and express expectations on the way other people should behave (or the way their actions should be assessed).

The character-defining element in this definition is the constitutive role of 'expectations' ${ }^{46}$ I have indicated above that normative guidance in itself does not force or even compel anyone to act upon it. Without further specification, this may give the impression that I claim that normative claims guide action solely through the intellectual or emotional force of practical reasons that substantively justify a given course of human action. But that would be a false impression. It seems to me that guidance through normative claims actually combines the rational appeal of substantive practical justifications with the practical weight of other people's expectations. Normative claims are not mere expressions of expectations concerning other people's behaviour. ${ }^{47}$ (They are not mere 'must-demands'

${ }^{44}$ Cf. Postema, G. J.: On the Universality of Moral Justification. In: Friedman, M. et al. (eds): Rights and Reason: Essays in Honor of Carl Wellman. Dordrecht, 2000, 93-94. In a sense, this justifies the positivists' insistence that the law is a 'social artefact'. See e.g. Mitrophanous, E.: Soft Positivism. Oxford Journal of Legal Studies, 17 (1997), 621-641, 622.

45 I note here that my characterisation drastically simplifies direct normativity in an important respect. A more complete account would also operate with the concept of 'normative statements': the propositional expressions of normative claims. Only claims that can be expressed as normative statements (as utterances in the context of specific discourses) qualify as normative claims. The distinction between normative claims and statements would be needed to account for detached attitudes to normative claims which play a crucial role in complex normative practices.

46 This feature of my account is primarily inspired by the distinction Niklas Luhmann draws between 'cognitive' and 'normative expectations'. See e.g. his Social Systems. Stanford, 1995, 330332. Luhmann, N.: Operational Closure and Structural Coupling: The Differentiation of the Legal System. Cardozo Law Review, 13 (1992), 1419-1441, 1426-1427. For another theoretical inspiration, see Llewellyn, K. N.: The Normative, the Legal, and the Law-Jobs: The Problem of Juristic Method. Yale Law Journal, 49 (1940), 1355-1400, 1368.

47 This is what distinguishes my account from imperative theories of law, despite the reliance on the concept of 'expectation'. 
or imperations. ${ }^{48}$ ) That is why normative claims are not generated without establishing some (at least, implicit) link with practical reasons justifying the normative qualification of the relevant forms of action. But the fact that the normative claims represent expectations is no less significant. ${ }^{49}$ When the addressee ponders the force of normative claims, she has to figure out the practical weight of the expectations they represent. By communicating expectations, normative claims bring into focus the addressee's relationships with relevant others.

This internal complexity of the action-guiding capacity of normative claims helps explain better how normative guidance is related to practical justification. Once again, we should remember that normative claims do not compel us directly to do what others tell us. Their primary job is to point to courses of action that can be regarded as more justifiable than others (or less justifiable than others) in light of reasons that relevant others find significant. Normative claims have a capacity to guide only if it somehow matters to the addressee that she does not subvert those expectations. It is also of crucial importance that justifying action in light of (direct) normative claims is slightly more specific than practical justification in general. The expectations that are manifested in the normative claims determine the discursive context for justification. If it matters to the addressee whether she subverts the pertinent expectations, the justification will have to rely on reasons that are recognised by the relevant others. (If it does not matter, the need to justify to them does not even arise.) The fact that the normative claim establishes a link between courses of action and practical reasons is as important (and informative) to the addressee as the fact that it purports to tell us what to do. The normative claim always implies an indication to the addressee of the reasons that relevant others will find particularly relevant for the justificatory assessment of her actions.

\section{Normative claims and practical reasons}

\subsection{The action guiding capacity of normative claims}

I have mentioned above that the normative claim we have set out to analyse ('treating people less favourably just because they are of a different colour or gender is wrong: if we truly respect the moral equality of persons, we must stand up against discrimination') has three structural elements: (1) making reference to a form of action; ${ }^{50}$ (2) subjecting the action to normative qualification; and (3) invoking practical reasons in support of the normative qualification. We can subject them now to a more profound analysis.

There are two relations between these structural elements that are constitutive of the normative character of the claim in question. The first is the interplay between the normative

${ }^{48}$ I take the notion of 'must-demands' from Matthew Kramer. See his In Defense of Legal Positivism: Law without Trimmings. Oxford, 1999, 84. For the concept of 'imperations', see Hare, R. M.: Sorting Out Ethics. Oxford, 1997, 11-12.

49 I use the term 'expectation' in a somewhat loose sense, mainly because I want to keep it compatible with what I say about the law below. When I say that normative claims represent expectations, I mean that there are others who care whether we act upon them or not. They are likely to criticise us, or even take actions against us, if we do not comply.

50 What I mean here is reference in a broad sense (cf. Searle: Speech Acts... op. cit. 26-27). It specifies what the normative claim is about - in terms of action, agent, temporal and geographical scope, limiting circumstances, etc. 
qualification and the addressed form of action. The way they are related to one another indicates what to do ('direct discrimination is to be avoided'). At the same time, it represents the expectations on the addressees' conduct ('we expect people not to discriminate, and we will criticise those who do'). The second connection is between the normative qualification and the invoked practical reasons. This is what distinguishes the normative claim from a mere must-demand. It is this connection that generates the normative claim's substantive justificatory force. It helps understand why one might think that direct discrimination is wrong, and warrants criticism ('direct discrimination is wrong because it is an affront to status equality').

\subsection{The success of normative claims}

Of course, this is far from adequate as it stands. ${ }^{51}$ We have to dig a bit deeper to figure out the capacity of normative claims to provide normative guidance. I sought to facilitate this investigation by my terminological choices. One of the reasons for talking only about normative 'claims' in this context (and not, say, 'norms') is that I want to emphasise that there may be utterances that attempt but fail to provide normative guidance. They remain mere claims - they remain 'unsuccessful'. ${ }^{52}$

What are the conditions of 'success' for a normative claim? First, it is important to see that, by 'success', I do not mean the ability to generate compliance. That is a conceptually different issue: the issue of the 'efficacy' of normative claims in my terminology. ${ }^{53}$ (And I will talk about it in some detail below.) In my account, 'success' refers to the ability of the normative claim to gain justificatory force in relation to the addressee's conduct. The normative claim is successful if it alters the conditions of justifiability for the addressee's behaviour in the context of specified human relations. ${ }^{54}$ It provides the background to a competent critical appraisal of the addressee's behaviour. ${ }^{55}$ The other side of this insight is that successful normative claims are able to justify the addressee in acting upon the expectation of others in the given circumstances - even if it means overriding her own preferences. ${ }^{56}$

51 There is a further complication about the relationship between normative claims and practical reasons that I set aside here. Normative claims can function as reasons themselves. (People are unlikely to be surprised if I say that the relevant piece of legislation is the reason for paying my income tax.) A normative claim (if successful) can function as a reason in itself, and can be used to establish further normative claims. I leave open this possibility with some reluctance: there are attractive theoretical advantages to treating normative claims as discursive constructions that channel reasons through discursive processes but that are not reasons themselves. But I simply do not have interpretive data at my disposal that would justify my theoretical preference.

52 The choice of terminology here is inspired by John Searle. See Speech Acts... op. cit. 54 (conditions for 'successful and non-defective performance') and 94 ('unsuccessful' acts).

53 I use Kelsenian terminology at this point. See e.g. Kelsen: Introduction to the Problems of Legal Theory. op. cit. 28-29.

54 To avoid misunderstanding, I emphasise that changing the conditions of justifiability is not the same as providing conclusive reasons. What is needed for the success of the normative claim is making a difference to justifiability. It may be enough that the normative claim manages to add a consideration that one's deliberation about justifiability must account for.

55 Cf. Hart: The Concept of Law. op. cit. 57.

56 Some might object that, right up to this point, I have failed to clarify what I mean by 'norms'. But it is only at this point that I can provide that clarification. In my account, norms are simply successful normative claims. 
Keeping the conditions of success and the ability of generating compliance apart is a key conceptual point in my account. Without maintaining that distinction, we would not be able adequately to characterise situations in which someone rightly criticises others for not complying with a certain normative standard. (The criticism would not be appropriate if it could not be based on a successful normative claim.)

How do the conditions of success look like for a normative claim? If we look back upon the structural features of our normative claim about direct discrimination, we soon realise that one can call into question its ability to change the conditions of justifiability for the addressee in two fundamental ways. One can doubt that it has managed to establish a justificatory connection between the normative qualification and relevant practical reasons (i.e. one can doubt that there are good substantive reasons not to discriminate). Alternatively, one can deny that those who make the normative claim are competent to set standards for the addressees. Their expectations do not matter to the addressees in terms of the justifiability of their behaviour. A normative claim is successful if it resists these two challenges.

I think we can capture these considerations by the claim that there are two types of practical reasons that must come together to constitute a successful normative claim. (1) There must be reasons providing a substantive justificatory background to the way given forms of action are normatively qualified in the normative claim. (2) There must also be reasons that underlie the competence of those who make the given normative claim.

I believe that the first aspect to the conditions of success is well understood and very well analysed in the literature. ${ }^{57}$ The second aspect ('competence') deserves more attention here. And we can start off from the fact that, in our actions, we continuously rely on the insight that normative claims owe their characteristic force partly to the normative position of those who formulate them. The same normative claim will have a very different impact on someone's behaviour if it is made by her father, child, boss, spiritual leader, neighbour or a complete stranger on the street. We also know that this 'differential' impact is not simply due to the fact that normative claims formulated by a knowledgeable agent tend to have more weight than claims by an obviously incompetent one. It is far more important that the practical weight of normative claims is inherently linked to the normative significance of the social position of those who formulate them. ${ }^{58}$ Only fathers and mothers can give parental advice to their children, only judges can make judicial decisions, and only the acting managers can rearrange the work-related responsibilities of the employees. Actually, it is easier to keep this consideration in focus if normative claims are construed as specific expectations. Expectations on one's action are always formed in a normatively prefigured social environment. Normative claims cannot provide normative guidance if they are not adjusted to the normative features of the relevant human relations. Normative claims presuppose a normatively relevant relationship between the claimant and the addressee.

57 Frederick Schauer has provided a profound analysis of how rules are conceptually linked with their 'rationale', 'justification' or even 'generating justification'. See his Playing by the Rules. Oxford, 1991, 5, 26, 53 and 74. My characterisation seeks to remain compatible with Schauer's claims when it comes to identifying the conditions of success for normative claims.

58 In a similar context, Andrei Marmor speaks about 'identity related' reasons (where the addressee's reason to $\varphi$ partly depends on the identity of another agent who suggests, requests, or orders the addressee to $\varphi$ ). See his Philosophy of Law. Princeton, 2011, 62. My competence criterion implies that direct normativity is always reliant on identity related reasons. 


\subsection{The problem of coercion}

One of the reasons why considerations about the conditions of success are conceptually important here is that they allow for a qualification without which the present analysis could not be plausible. Accounts of normative guidance have to reckon with the mode of guiding behaviour exemplified by coercion. What we have to think of is not direct physical duress where the intention of the agent is made irrelevant (e.g. someone is chained to a seat and taken somewhere). What I am talking about could be characterised as 'indirect duress'. It occurs when others create a situation in which the addressee adjusts her intentions as a response to the pressure deliberately applied to her. The addressee herself decides to act against her original or preferred intentions. The textbook cases of this kind of 'guidance' are well known: someone is forced by a gunman, scared into submission, blackmailed with a piece of sensitive information, etc. The confusing aspect of coercion here is that, in many respects, it meets the criteria we have set for the success of normative claims. We can definitely say that the actions of those who 'coerce' are sources of reasons for the addressee, and that they alter the conditions of justifiability for the addressee's own behaviour. (It may be that, an hour ago, I was justified in my intention to go to work but, now that someone holds me at gunpoint, it is no longer reasonable to persist with my original plan.)

No doubt, there are important overlaps between mere coercion and successful normative claims but it would be profoundly implausible to depict mere coercion as an example of normative guidance. ${ }^{59}$ I hope that we can avoid the implausibility here by relying on what has been said about the 'condition of competence' for successful normative claims. Mere coercion does not meet that condition - even if it has the capacity to give reasons to act in a certain way. Coercion does not constitute normative guidance when it lacks plausible justification in the dimension of competence. ${ }^{60}$ It is not an instance of successful normative claims. ${ }^{61}$

Of course, the relationship between normative guidance and coercion is not without further complications. Coercion and normative guidance are not simply opposed to one another. There are cases of coercion that fall within the realm of normative guidance. There are agents whose normative competence extends to the capacity to add extra practical weight to their normative claims by resorting to some form of coercion. Most importantly for us, there are authorities who are entitled to threaten addressees with punishment. It is true of the public attorney who can prosecute a suspected criminal, the judge who can send a defendant to jail, the official who can impose a fine, the teacher who can fail a student, and the parent who can discipline a disobeying child. But the cases of 'justified coercion' should not subvert the conceptual relations here. It seems clear enough that, in the cases of justified coercion, it is never the coercive act itself that makes the guidance of action

59 See Hart: The Concept of Law. op. cit. 19.

${ }^{60}$ One could characterise the relationship between normative claims and illegitimate coercion more accurately. I set aside a number of finer points here. E.g. we can say that successful normative claims establish a justified demand on the addressee. This is an element that is missing when someone, without authorisation, forces others to do something. The victims of illegitimate coercion must do what they are asked to do but not because they owe it. Cf. Hart: The Concept of Law. op. cit. 19-24 and 27.

61 I do not mean that illegitimate coercion does not constitute practical guidance. On the contrary, mere physical threats are very good at guiding action. But it is not normative guidance. 
normative. ${ }^{62}$ In fact, the imposition of coercion is justified only because it enjoys justificatory support from normative claims that are successful quite independently of the capacity to coerce. Justified coercion is always parasitic on successful normative claims.

\subsection{Success, efficacy and the idea of normative guidance}

Above, I have introduced the conditions of success for normative claims by contrasting them with the conditions of efficacy (that is, the ability to generate compliance). I have claimed that a successful normative claim does not need to be efficacious in generating compliance for each addressee, at all times. (This is the conceptual precondition for criticising addressees for not complying with a normative claim.)

But does this mean that, for a normative claim, the ability to provide normative guidance is simply a matter of meeting the conditions of success? Well, that that would be counter-intuitive at best. It would run contrary to conceptual claims I have made earlier. I have identified at least one mode of guidance that is not normative (i.e. mere coercion). That turns normative guidance into a subcategory of 'guidance' (or 'practical guidance', to be more accurate). And that broader category of guidance must be, at least partly, a matter of efficacy: getting people to do what others expect them to do. Also, I have claimed above that the idea of compliance is constitutive of normative guidance. These conceptual links would be broken if we accepted the possibility of instances of normative guidance that do not in fact guide anyone. Too much of my analysis would be undermined without admitting that a measure of efficacy for normative claims is also constitutive of the concept of normative guidance.

It suggests that normative guidance can be broken down to two aspects: (1) changing the conditions of justifiability for the addressees; and (2) the capacity to generate compliance. Without the second aspect, the normative claim does not guide, and without the first, the guidance is not normative. The idea of normative guidance implies that there is a (systematic) impact on what people do, and that this impact is driven by successful normative claims.

\subsection{The ability to generate compliance}

There is a need to provide further clarification of the conditions for efficacy for a normative claim (for its ability to generate compliance). More specifically, I will ask how normative claims can generate reasons for the addressees that facilitate compliance. At first, it might seem like an unnecessary repetition of a point discussed above. I have claimed that practical reasons are part of the basic structure of normative claims: certain types of them are conditions of their success. However, we should not forget that success and efficacy are two different (though related) aspects of normative claims. It should not be assumed that there is a conceptual guarantee that the role of reasons in generating successful normative claims will not be significantly different from the role of reasons in facilitating compliance by particular addressees. A plausible account of normativity needs to accommodate the possibility that the addressees comply with a normative claim for reasons that are different to the reasons that make the claim itself successful. Normative claims exploit the dynamics of human relations in a broad variety of ways.

62 Cf. MacCormick: Institutions of Law. op. cit. 108. 
We can appreciate the significance of this distinction a lot better if we realise an important contextual difference between reasons that make the normative claim successful and the reasons that facilitate compliance. The reasons that we can associate with the conditions of success are specified for the justificatory needs of the normative claim. As I have said above, they must open up a perspective that is common to the claimants and the addressees: they are there to facilitate mutually acceptable judgments on the pertinent action problems. Quite obviously, this perspective plays no necessary or constitutive role in the reasons that facilitate compliance. Compliance should make sense from the addressee's individual perspective - it must be a good idea to them to choose to comply in the given circumstances (even when it is burdensome or even painful).

This point becomes clearer as soon as we realise that the mere fact of compliance does not tell us much about the reasons that actually facilitated it. Different addressees have different practical outlooks, and efficient guidance of action is only possible if the relevant normative claims are capable of fitting into different practical outlooks. The conceptual possibility of generating a variety of different reasons for compliance is built into each normative claim. It is one of their conceptual characteristics.

It does not mean that reasons for compliance can become unrelated to the reasons that constitute the success of the pertinent normative claim. (That would erroneously equate compliance with mere conformity.) Normative guidance presupposes that it is due, at least partly, to the normative claim that the addressee acts in a particular way. It seems to me that the reasons for compliance must remain related, in particular, to the conditions of competence for the normative claim. The expectations of important others must be constitutive of the specific practical significance of the normative claim for the addressees. It seems far less plausible to claim that the background justification to the normative claim has a necessary role to play in reasons for compliance. In fact, when the background justification takes centre stage, it is not obvious whether the normative claim has managed to guide the action at all. ${ }^{63}$ We should not forget that the practical significance of the background justification is independent of the normative claim. (Otherwise, it could not justify it.) That is why it seems plausible to me that the practical difference that the normative claim makes (in terms of compliance) must derive primarily from the expectations it represents. So, the question about reasons for compliance boils down to figuring out how the expectations of relevant others can matter to the addressee, and how to capture that in terms of reasons.

We can usefully test the plausibility of this claim by outlining three different 'scenarios' of compliance that are eminently meaningful to any addressee with normal social skills. (I formulate all these scenarios in terms of the practical weight of the expectations represented by the relevant normative claims.)

63 This obviously resonates with what certain positivists (and Scott Shapiro in particular) say on the so-called 'practical difference thesis'. The thesis captures the insight that, if the reasons that constitute the rationale of a normative claim guide directly, the normative claim itself becomes redundant. Hence, if laws are to make a difference to their addressees' conduct, they cannot guide simply through the rational appeal of underlying reasons. See Shapiro, S. J.: The Difference That Rules Make. In: Brian, B. (ed.): Analyzing Law: New Essays in Legal Theory. Oxford, 1998. Shapiro, S. J.: On Hart's Way Out. In: Jules Coleman (ed.): Hart's Postscript: Essays on the Postscript to the Concept of Law. Oxford, 2001, 178-179. See also Coleman: The Practice of Principle. op. cit. 69. I believe we do justice to the plausible insight here by emphasising that the action-guiding capacity of normative claims is inherently dependent on the fact that they manifest expectations. 
(1) For one, faced with a normative claim, the addressee might think that the need to comply follows from her own moral commitments, as well as the moral character of her relationship with those who formulated the expectations. By not acting on their expectations, the addressee would make a moral mistake - making her action blatantly unjustifiable. There are relevant others to whom compliance with the given normative claim is owed. The addressee would fail relevant others by not complying: she would invite a criticism that even she would be forced to accept as justified.

(2) The addressee might also think that the moral weight of the expectations manifested in the normative claim is irrelevant. However, she may take more seriously the prospect that ignoring the expectations on her behaviour can make it more difficult to cooperate with the relevant others. (They would no longer be inclined to employ her, to do business with her, to play with her, to keep her in the loop, to extend certain benefits to her, etc.) If the continued cooperation, the maintenance of social relations is important to the addressee, it would be silly not to act upon the expectations that were important enough for them to be formulated as normative requirements. Compliance often comes with attractive benefits addressees are sensitive to.

(3) Apart from being unmoved by the moral aspect of the normative claim, the addressee might also be indifferent to the prospective benefits of cooperating with those who have expectations on her behaviour. Nevertheless, she might be sensitive to the fact that they have enough power or social influence to force her to take their expectations seriously. She does not want to find herself in open, and potentially perilous, conflict with them. Meeting their expectations may be burdensome but its costs are dwarfed by the possible losses the addressee can suffer if they turn their power against her. If she does not want to suffer unreasonable losses, she would be stupid to ignore their expectations.

Of course, by outlining these three scenarios, I do not seek to capture all the possible ways in which one can find reasons to act upon normative expectations. There may be innumerable other ways as well - some of them are more complicated or even more exotic. (Someone may comply out of blind habit, in unreflective deference to a tradition, or with a view to manipulating certain human relations.) But these three scenarios are more fundamental than others exactly because, as I have said above, they are eminently meaningful to anyone with normal social skills. We constantly read other people's behaviour in light of the motivations that are at work here, and rely on them in our efforts to influence other people's behaviour. ${ }^{64}$ They are deeply ingrained in our social practices, and determine how we design them.

These considerations will have a crucial role in characterising the normativity of law in Part II. For that reason, we need to find a proper terminological focus for them. We can try to characterise more accurately the types of reasons that make these three 'scenarios' possible.

I organise this further clarification around the simple (and rather under-reflected) idea that everybody has aims that are constitutive of her practical orientations, and often even

64 A more complete analysis of normative guidance and the ability of normative claims to generate compliance would need to account for the relationship between practical reasons and the empirical psychological factors that actually guide behaviour: motives. By definition, the agent performs an action only if she is motivated accordingly. For a revealing account of the conceptual relation, see Grice, G. R.: Motive and Reason. In: Joseph, R. (ed.): Practical Reasoning. Oxford, 1978. See also Anscombe: Intention. op. cit. 17-18. 
her identity. People are sensitive to practical reasons that touch upon such 'personal aims' ${ }^{65}$ Of course, the relationship between personal aims and practical reasons is complex. What I need here is just one insight about that relationship: we need to take a distinction between two fundamental ways in which they can be related to one another. On the one hand, the practical weight of certain reasons may be fully reducible to personal aims: they have a justificatory force because acting on them makes sense in light of one's personal aims. In an important sense, such reasons have action-guiding capacity that is instrumental to one's given personal aims. We can call them instrumental reasons. (They can also be termed prudential reasons.) On the other hand, there are reasons whose practical weight is not (or not wholly) determined by personal aims. They are inherently associated with values that form part of one's identity: they are constitutive of one's personal aims. They cannot be fully reduced to personal aims; on the contrary, one's personal aims can be (at least partly) reduced to them. Such reasons are non-instrumental. We act upon non-instrumental reasons not because it promises some benefit or fends off harms but because it would be uncharacteristic of us not to act upon them. We would not look ourselves.

If we inquire further, we see that instrumental reasons can be associated with one's personal aims in two basic ways. One is when, so to say, the reasons run parallel with personal aims: acting on them promises to promote those aims (to facilitate their realisation). This is what we saw in action in scenario (2). If we want to give a name to this mechanism, we can say that normative claims can provide 'benefit reasons'.

The other characteristic way of providing instrumental reasons is based on creating situations in which the addressee sees her personal aims threatened. When the addressee faces the prospect of her aims being frustrated, she is bound to perceive the normative claims as strong prudential reasons. She will be motivated to comply to avoid the materialisation of the threats. This is compliance as characterised in scenario (3) above. The mechanism of coercion, that we have analysed in a previous subsection, also exemplifies this possibility. We can say that, when the normative claims become efficacious this way, compliance is a sort of response to pressure. I will call the reasons that generate this mode of compliance 'response reasons' ${ }^{66}$

I believe that the way instrumental reasons are related to compliance is relatively straightforward. The pattern of the relationship between personal aims and non-instrumental reasons raises trickier issues. The way it was reflected in the first scenario of compliance above makes it quite obvious that the non-instrumental reasons we are talking about here are very much likely to take the form of moral reasons. ${ }^{67}$ (In fact, I struggle to find instances of non-instrumental reasons that we would not characterise as moral reasons.) But we have

65 The idea that we can characterise the impact of normative claims on the addressees in terms of 'aims' they pursue is borrowed from Hart. See his: Essays in Jurisprudence and Philosophy. op. cit. 113. It is not an accident that I do not talk here of 'individual aims'. One can identify oneself with collective aims which then become personal (although not individual) aims.

66 The distinction I draw between 'benefit reasons' and 'response reasons' is inspired by Gerald Postema. He talks about 'compliance reasons' and 'response reasons' See Postema: Jurisprudence as Practical Philosophy. op. cit. 346-348. Due to the way I conceptualise 'compliance' here, I needed to deviate from Postema's analysis, and adjust the terminology.

67 Some scholars argue that the contrast between moral and prudential reasons is dubious. See e.g. Perry, M. J.: The Idea of Human Rights: Four Inquiries. New York-Oxford, 31. I have derived the distinction from the contrast between instrumental and non-instrumental reasons in anticipation of objections like those raised by Perry. 
to be more specific. The reasons that provide non-instrumental reasons for compliance are not just any kind of moral reasons. They must be reasons that make it a good idea to comply from the addressee's individual perspective. They must be tailored to the addressee's identity. In an important sense, they must be 'identity-related' reasons. ${ }^{68}$ They must be inherently linked to the importance for the addressee to stay true to herself, and not to fail important others.

We also have to be more specific about the sense in which the law generates moral reasons for compliance. It is not that a normative claim must be seen as seeking to change one's moral outlook. (That is the kind of practical impact that a normative claim is unlikely to achieve in itself.) What a normative claim can achieve is establishing a specific responsibility for compliance that is in line with the addressee's own moral outlook. It can be attained by making it clear that there are others for whom the normative claim is important, and who rely on the addressee for her compliance. If those are important others with whom the addressee has a morally relevant relationship (and if compliance fits the parameters of their relationship), the expectations (that the normative claim comes to represent) take on specific moral significance. ${ }^{69}$ It becomes a matter of moral responsibility for the addressee not to fail the relevant others. A normative tie is created between the addressee and the relevant others that can only be captured in terms of moral reasons.

\subsection{The action-guiding capacity of the condemnation of direct discrimination}

It is time to return to our example of the normative claim condemning direct discrimination ('treating people less favourably just because they are of a different colour or gender is wrong: if we truly respect the moral equality of persons, we must stand up against discrimination'). We can answer now the question whether it was capable of normative guidance before it was written into law.

My account of normativity ended up characterising normative guidance in terms of five types of reasons. Reasons arising from a background justification and reasons for taking seriously the expectations it represents can make a normative claim successful. And its ability to generate moral, benefit and response reasons enables it to attract some level of compliance. If these are the criteria, we can safely say that the condemnation of direct discrimination was a successful normative claim well before it was made part of statutory law - for at least a section of British society. For those who were committed participants of the liberal moral and political discourses (in which the normative claim was formulated in the first place), it changed the conditions of justifiability for their conduct. They were also

68 Cf. Marmor: Philosophy of Law. op. cit. 62. I significantly extend the concept of 'identityrelated reason' compared to Marmor's analysis.

${ }^{69}$ I note that the type of moral reason I try to articulate here is not without legal doctrinal relevance. E.g. it is known to play a role in debates over 'prisoner disenfranchisement.' In such cases, governments tend to argue (among others) that criminals have failed the democratic community by committing crimes, and that is the reason why it is fair to strip them of the right to vote (the argument from 'civic responsibility'). For judicial assessments of the argument, see Sauvé v Attorney General of Canada (No.2) [2000] 2 C.F., Hirst v United Kingdom (No.2) [2006] 42 EHRR 41. The courts typically accept this argument as legitimate (see Hirst §§74-75), although it can be outweighed by other considerations (as it happened in both Hirst and Sauvé). The plausibility of the argument presupposes that, apart from the threat of punishment, citizens have a specific moral reason to comply with the law. 
unlikely to call into the question the normative competence of those made claims about the unacceptability of direct discrimination. The normative claim was also capable of generating a measure of compliance. Those who supported the fight against discrimination on moral grounds were motivated not to discriminate. Some others were motivated to comply because they wanted to remain on good terms with those who were passionate about this issue. And further others might have wanted to avoid the wrath of political campaigners (e.g. negative publicity or a boycott on their businesses).

Of course, this may have left out large swathes of the population (perhaps the majority of it) who did not comply and were not motivated to comply. But we can say that, within the bounds of particular moral and political discourses, the condemnation of direct discrimination was a successful normative claim well before it was written into law. Whatever legal institutionalisation did to it, it did not include creating a claim capable of normative guidance. Guidance by the normative claim was reconstituted, rather than constituted, in the process of turning it into a statutory obligation. 